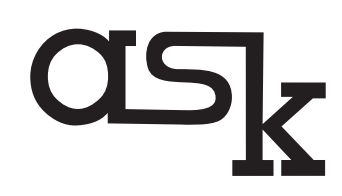

Research \& Methods ISSN 1234-9224, e-ISSN 2544-0799 Vol. 29 (1, 2020): 55-73

The Ohio State University Libraries

Columbus, Ohio, USA

Institute of Philosophy and Sociology

Polish Academy of Sciences, Warsaw, Poland

www.askresearchandmethods.org

https://doi.org/10.18061/ask.v29i1.0004

\title{
Online qualitative research in immigrant communities: opportunities and challenges during the pandemic*
}

\author{
Katarzyna Andrejuk \\ Institute of Philosophy and Sociology, Polish Academy of Sciences
}

\begin{abstract}
Internet-based qualitative methods have quickly transitioned from a niche to mass research strategy. The aim of the article is to describe the opportunities and challenges of online research, with a focus on in-depth interviews through video communication tools such as Zoom, Skype and Face Time. The analysis encompasses various dimensions of internet-based research: recruitment, conducting empirical study, analysis, and archiving. Online qualitative methods may be particularly useful in studying immigrant populations, due to a high level of internet skills among immigrants and their familiarity with online video communication resulting from their everyday transnational activities. Online research may translate into the increased visibility of low-cost projects, and broaden the academic autonomy of junior researchers, thus enhancing the diversification of empirical, theoretical, and methodological approaches. Conducting online interviews also improves the quality of archived material, due to the access to both sound and visual recording. The text emphasizes the advantages of the hybrid approach to qualitative research through combining online and offline interviews, and online and offline participant observation. The author refers to experiences of data collection for a study of Polish migrant entrepreneurs in the UK.
\end{abstract}

Key words: internet-based interviews; online interviews; Zoom and Skype interviews; internet-based qualitative research; digitalization of qualitative research

* The project was financed by the Polish National Agency for Academic Exchange within the Bekker programme, contract number PPN/BEK/2019/1/00200/U/00001. 
In a very short time, internet-based qualitative research has gone from a niche to mass method. Although it has been known for decades, its popularity is currently growing rapidly. The internet has democratized access and the technological skills of its users have improved. Advanced applications enable their users longdistance video communication. The social media, which are the source of rich empirical data, are also growing in number and popularity. The prevalence of online methods, including in-depth interviews, has only been compounded by the coronavirus pandemic and the social-distancing rules applied by both researchers and respondents. They replace face-to-face contact with methods which recreate the situation of a direct conversation without involving the health risks.

The notion of "online qualitative methods" is very broad and encompasses a variety of activities, which are diverse with regard to their level of technological complexity or empirical autonomy. Different strategies and techniques which have been used across recent decades have been modified and adapted to new circumstances as digital technologies have progressed. One may distinguish three phases in the development of qualitative internet-based research. They differ with regard to the degree of advancement of the technologies used, the tools and applications in use, as well as the internet access and internet skills of various target groups and respondents. The essential breakthrough was the gradual popularization of Web 2.0, specifically the growing interactivity of the internet, which has enabled the broad participation of users, collaboration and the exchange of ideas. The first wave of online research encompassed mostly asynchronous methods (e.g. e-mail interviews), online desk research, and chatroom messaging without video communication. In 2008, Ulf-Dietrich Reips enumerated the following activities as online research methods: nonreactive web-based methods (study of mailing lists, $\log$ file analysis), web surveys, and web-based psychological testing and experiments (Reips 2008). The fact that online in-depth interviewing was not on that list proves that just over a decade ago it was relatively less common than other online methods. Qualitative internet-based research was in an early stage of development, and the focus was on email interviews and instant messaging (Kazmer, Xie 2008; Meho 2006; Stieger, Göritz 2006; O’Connor, Madge 2003). These methods were praised for eliminating the need for transcription, which was stated to be often connected with errors, miscommunication, and "tidying up" the data (Bowers, Hamilton 2006: 828, 831). However, it was quickly pointed out that "some participants may not be as effective writers as they are speakers" (Karchmer, 2001; Kazmer, Xie 2008: 1289).

The proliferation of video calls and video communications applications marked the transition to the second wave of online sociological research: it became a more commonly used method also for synchronous in-depth interviewing. Social researchers using internet-based methods focused on video calls such as Skype 
and Zoom for in-depth interviews (Weller 2017; Symonds et al. 2016; Sullivan 2012; Janghorban et al. 2014; Archibald et al. 2019). The increased popularity of video communication enabled the development of internet-based qualitative methodology and conducting of internet interviews, which not only gathered information about participants, but also allowed them to interact with researchers in a more in-depth manner. Online methods have been found particularly useful in researching hard-to-reach populations, consisting of individuals seeking anonymity or residing in geographic dispersion (Wilkerson et al. 2014).

The third phase of internet-based research added the context of coronavirus and legitimized online research as a strategy compliant with sanitary restrictions, and as a safe method for both the researchers and research participants. The improvement in video communication has provoked some reflection on the equivalence of internet-based and face-to-face interviews. The pandemic may also have longlasting effects on the patterns of internet-based activities, having led to people's increasing familiarity with advanced software platforms for video calls and video conferencing. Not only researchers, but also research participants use online meeting tools on a daily basis, which lessens the potential distrust towards this method, and improves response rate and readiness to participate in web interviews. On the other hand, the prevalence of online meetings has led to increasing technostress or what is known as "Zoom fatigue", a negative consequence of the huge popularity of remote work during the pandemic (Richter 2020; Wiederholt 2020; Fosslien, West Duffy 2020). The situation of an interview is characterized by a higher level of interactivity and involvement of meeting participants than an average collective video conference; therefore, it is less burdened by particular risks connected with Zoom fatigue, such as the sense of alienation, and attention deficiency during mass online events.

The aim of the article is to describe the main advantages of using internetbased methods in qualitative research on migrant communities, as well as to indicate potential problems and strategies for their solution. Some features of computer-mediated communication may affect the content of the message as much as the personality of the researcher, their preparedness for an interview, and the surroundings and location of both the interviewer and interviewee. The text aims to demonstrate how the unique traits of qualitative methodology, which are partly different than in the case of survey research, translate into particular challenges when conducting internet-based research. The analysis examines the consecutive methodological stages, such as recruitment, conducting in-depth interviews online, and archiving. The study refers to research conducted in 2020 in the Polish community in the UK (self-employed individuals and entrepreneurs). The aim of the qualitative research was to achieve a maximally diversified sample (heterogeneity sampling). The researcher looked for contacts in social media 
and business sites, using snowball sampling and private networks - different than migrant entrepreneurs. The project applied hybrid online/offline methods, combining face-to-face interviews, Zoom interviews, and participant observation both offline and online. This approach is consistent with the reiterating claims for using the unique form of mixed-mode interviewing, whereby online and offline methods are complementary and can be used simultaneously in a research project (Meho 2006; Mirick, Wladkowski 2019).

\section{ONLINE RECRUITMENT AND PARTICULARITIES OF SAMPLE SELECTION IN QUALITATIVE RESEARCH}

Quantitative and qualitative research differ with regard to their strategies of sample composition, which is also associated with the acceptability and functionality of online interviews. Surveys aim at a representative sample which would reflect the socio-demographic structure of the population. In-depth interviews focus on the subjective narratives of people rather than parameters of aggregated variables and datasets. Qualitative research aims at an in-depth representation of individual experiences. It mostly attempts to create a heterogeneity sample: approaching respondents who represent the most diversified socio-demographic profiles, which translates into the diversity of their experiences and varied narratives (see e.g. Strauss, Corbin 1998; Robinson 2014). While a scarce number of respondents representing a certain group in a quantitative study may be compensated through weighting procedures, in qualitative research there is no method or strategy to compensate for the insufficient heterogeneity of the sample. In this context, recruiting various informants who provide unique narratives appears to be all the more important.

Online interviews imply also online recruitment strategies; moreover, even in the case of face-to-face interviews, the recruitment phase is often mediated through internet and email communication. The usefulness of online recruitment depends on the community under study. Digital exclusion usually concerns elderly and uneducated individuals (Helsper, Reisdorf 2016). Online interviews may be more effective in studies of highly-skilled or young individuals (although some research suggests that older respondents may be more willing to learn and eager to use online video communication tools - see Lo Iacono et al. 2016: 5). The usefulness of online qualitative research must be evaluated in the light of the characteristics of the given group and the potential digital participation of its participants. Such studies seem to be more beneficial in researching small populations with a unique demographic profile, rather than cross-sectional research encompassing the whole of society. In some small groups, online interviews may improve the quality of research, while in other cases the sole reliance on online research may distort the sample, deform the study or be useless. Undoubtedly, they would not constitute 
a convenient method of studying hunters-gatherers in Amazonia, homeless people, or elderly patients in nursing homes. Immigrants, in general, are located on the second extreme of the "digital divide" spectrum: online research may be a valuable method of learning about their lives and customs.

Migrants are a unique group in terms of the patterns of internet use. Their daily lives are embedded in transnational spaces and connected with transnational activities, which require the frequent use of information and communication technologies - ICT (Vertovec 2009; Faist, Fauser, Reisenauer 2013; Oiarzabal, Reips 2012). Internet-based research may be useful, for example, for studying how online tools support the establishment and the strengthening of immigrant communities (Kissau, Hunger 2010). However, it has long been established that various forms of online research may be convenient not only for examining activities on the internet, but also for offline activities (Mann, Stewart 2000: 5; Salmons 2014: XVII). International migrations, globalization and ICT development are inseparably connected. Immigrants use online tools in their everyday activities to communicate with family abroad, build support groups in social media, maintain transnational ties in social networks, and contact state officials and administrations (often holding citizenship of a country other than the one in which they reside). Of course, immigrants are not a homogeneous group; some segments and groups may also be digitally excluded due to similar factors as those of the general population (age, limited access to financial resources). Specifically, refugees were identified as a group who may experience particular difficulties in access to the web (Alam, Imran 2015). Even though internet access can be restricted due to the uncertain status of some migrant groups, their modest financial capabilities and insufficient infrastructure, foreigners demonstrate creative ways of overcoming these limitations in order to remain connected to the web (Alencar 2020, citing i.a. Wall et al., 2017; Witteborn, 2015; Maitland \& Xu, 2015; Smets, 2018). These research findings from multiple projects confirm that internet access is a priority for migrants; digital skills and frequency of internet use are particularly high among migrants, even in the case of unprivileged and discriminated groups such as refugees (Kutscher, Kress 2016; Alencar 2020).

In the case of self-employed migrants, the prevalence of internet use may stem not only from their migration status, but also their level of skills, innovativeness, and general resourcefulness. The group under study (migrant entrepreneurs in the UK) also used internet for professional activities, business meetings, networking, establishing and maintaining contacts with customers, and consulting. Online activities are deeply embedded in immigrant lifestyle; such individuals also have good digital skills and are familiar with various video communication tools. The internet challenges and revises the methodological standard of observing individuals/groups in geographical spaces where they are present and active. 
Although multi-sited ethnography is typically identified with the coexistence of multiple physical and territorial localizations within the same research design (Boccagni 2020), the transition of many activities to the online sphere justifies and rationalizes treating the virtual settings seriously as geographical sites (Wittel 2000). The prevalence and variety of online social practices means that in qualitative studies of migration/the labour market, the internet should be regarded as one of the "sites" of multi-sited ethnography, where the researcher's presence is necessary to fully capture and understand the social processes happening in different locations.

\section{INTERNET-BASED RESEARCH AS A STRATEGY OF DIVERSIFICATION OF QUALITATIVE METHODOLOGY}

Internet-based research should be perceived as an aspect of research diversification, which allows researchers to better grasp the social reality of respondents. This aim is often achieved through mixed research methods, or data triangulation within a project (Archibald 2016; Konecki 2008). Diversification may have different meanings (Denzin 1978); however, in general, its goal is research optimization, i.e. to obtain comprehensive empirical data which are not burdened with the errors originating from a single, constantly applied research procedure. Methodological diversification does not necessarily mean a combination of the qualitative and quantitative approaches: it may be achieved through the multiplicity of qualitative methods. Moreover, in research focused around just one method, a diversity of tools and research protocols may also occur. This also happens in migration research, where one can observe not only diversification of methods, but also tools and approaches within a single method. Within in-depth interviews, there are projects of longitudinal studies, panels which envisage returning to the same respondents after a certain period. In addition to that, qualitative research is based on combining in-depth interviews with other methods, such as participant observation and autoethnography (insight into the researcher's own experiences). They are treated as complementary: one method usually becomes the main one and the others help in acquiring additional information or in the comprehensive interpretation of data. Limiting the research to just a single method may impoverish the results and give them a fragmentary character.

Migration research also places an emphasis on the diversity of results achieved by "outsider" and "insider" researchers. Those interviewers who are migrants themselves may more easily approach individuals who are weakly adapted to the host society, live on the margins or do not possess social skills to enable them to fully participate in the everyday life of the host country. In such situations, researchers with a migration background may be more successful in gaining the 
trust of potential respondents. Another significant issue is the familiarity with the informants' language and possibility of conducting interviews using the mother tongue of an interviewee. The level of cultural difference between a researcher and an informant creates a context in which a conversation develops (however, this includes not only the migrant/non-migrant status, but also other factors such as class, gender or religion - see Carling et al. 2014). The issue of who is asking the question may also influence the content of the response. The answers and narratives resulting from open questions may significantly differ depending on who is listening: some elements may be omitted, while others may be presented in a context that is adapted to the respondent's perception of a certain investigator, their nationality, and anticipated attitudes. (An interesting example is an article by A. Wylegała, which analyzed the content of interviews conducted by Polish and Ukrainian researchers with the same person - see Wylegała 2013).

Using online research tools may be treated as an additional aspect of research diversification. In this sense, triangulation is not limited to diversifying researchers, data, theories or methods (as in Denzin's (1978) approach). It also encompasses the triangulation of the transmission channel and the way of mediating the meeting with a respondent. From the perspective of the scientific value of empirical data, it is important that internet-based activity facilitates a return to the same respondents by, for example, repeat interviews with the same participants. This possibility is crucial, not only in longitudinal panel studies, but also in one-off research in order to collect additional information. It allows a researcher to be more independent from temporary indispositions or respondents cutting short the interview owing to other duties.

In a broad sense, diversification encompasses not only the methods of conducting research, but also the profile of projects (one-person or team projects). The online component in qualitative research also enhances the significance of individual low-cost projects. Cost-efficiency has always been highlighted as one of the huge advantages of online research (Stieger, Göritz 2006; Nehls et al. 2015; Archibald et al. 2019; Gray et al. 2020; Krouwel et al. 2019). Moreover, it may translate into increased visibility of projects of junior researchers which tend to be lower-cost. Projects which envisage business travel - e.g. for fieldwork and interviews - are more expensive and typically involve more researchers. In the early stages of an academic career, online research may broaden the academic autonomy of individuals without large teams at their disposal and who have not yet been awarded large grants. Internet-based research is possible for a single researcher, even when offline projects with a similar number of respondents would have to be conducted by a larger team. By making research independence possible, online research also enhances the diversification of conceptual, theoretical and methodological approaches, which may be rejected in large grant competitions (on 
reviewer conservatism, see Guthrie et al. 2019). Online qualitative methods also allow academics to conduct a more extensive preliminary research as preparation for applications for advanced research projects.

However, using video-conferencing tools may have a positive impact not only on one-person projects but also on larger scientific endeavours. Thanks to access to visual and audio dimensions of an interview, a more in-depth interpretation may be conducted not only by the researcher conducting the conversation, but also other academics working in a given project. Audio-video recordings also allow for better supervision and control of investigators' work. The principal investigator may be more effective in checking the interview performance of sub-contractors and advising on how to improve research conduct. The possibility to record both audio and video also broadens the opportunities for archiving.

Additional implications and nuances of qualitative internet-based research become visible when one explores the economic context of actual research practice, connected with travel and the financial framework of scientific tasks. Migration projects often involve a research phase abroad, including the costs of transport and accommodation. Attempting to lower the costs (especially with the goal of raising competitiveness in grant applications and avoiding the criticism of reviewers concerning financial extravagance) may lead to limiting the research to the context of a single city, or at least reducing the costs and length of research stays outside the location of the academic centre where the investigators are employed. This has an impact on the quality of research, such as withdrawing from empirical studies in smaller towns where only a few respondents reside in favour of larger cities where multiple interviews can be conducted in a short time. In the meantime, the experiences of migrants residing in small towns where foreign groups are not numerous may be unique and different. Failure to capture this context in research trivializes and oversimplifies observations and findings. Conducting at least some parts of research online allows one to take into account respondents residing in smaller towns, or locations which are not well served by transport connections. At the same time, it does not increase the costs of research, which is significant in the case of grant applications. As Iacono et. al point out (2016: 8), reducing business travel also constitutes an environmentally friendly approach. In the cases of hard-to-access countries, conducting online research may be a good solution in crisis situations, such as refusing a visa to researchers whose projects concern sensitive political issues and who may be treated as persona non grata in a certain country. 


\section{INTERACTIONIST DIMENSION OF AN INTERVIEW AND THE SEMANTICS OF THE COMMUNICATION CHANNEL}

The communication channel is never completely transparent: it is loaded with certain meanings and qualities itself. These meanings arise, for example, from the accessibility of the medium for various social groups, its accuracy in recreating a real-life meeting, or the perception of the channel by interaction participants. The issues of sample selection and the context of the digital divide were discussed above. Two more aspects require additional attention in online social research: the interactionist (communication) and the technological dimension.

In the case of online qualitative methods, the communication dimension seems more essential than during survey research. In-depth interviews rely on open questions. The responses are shaped, among other things, by the personal engagement of a participant in the conversation; the information provided is not a simple derivative of the question asked. The content of a narrative depends also on the relational dimension of the conversation, and the ability to make a connection and bond with a participant. Therefore, in qualitative research the interactionist contexts of a conversation, beyond the interview scenario, play an important role. Body language, facial expressions, outfit, environment of home or office where an interview takes place - all shape the final outcome of a meeting. The video aspect appears to be an important component of empirical research, and face-to-face interviews cannot be simply substituted by telephone interviews. The situation of a meeting as such, getting to know the respondent - is of high research relevance. It translates into a better personalization of questions in biographical, half-structured, and unstructured research. On the other hand, another factor may be the psychological construction of "effort" and "reciprocity", i.e. the individual perception of work which has to be put into a travel and meeting in person. Since in offline fieldwork the labour involved at the pre-interview stage is more evident and visible to interviewees, they may treat the offline conversation and questions they are asked more seriously during such meeting.

Face-to-face interviews allow the researcher to control more effectively whether the conversation takes place in the presence of third persons or just between the interviewer and an interviewee. Online interviews do not always make it possible to determine whether other individuals are present and participating (out of sight of the computer camera). Such third persons may influence the answers given, avoidance of certain topics or emphasizing others, or the general narrative strategy. Nonetheless, it should be noted that face-to-face interviews often take place in public spaces such as cafes or popular meeting points - they are not conducted in seclusion. In this context, the opportunity for both the respondent and the interviewer to participate in the meeting from a safe, private location, such 
as the home, is cited as one of the advantages of online conversations (Sullivan 2012: 58; Lo Iacono et al. 2016).

The epistemic value of various modes of scientific conduct and communication channels depends, among other things, on the issues under examination. Online research introduces many intermediary degrees between the full resemblance of offline (face-to-face) meetings and email-only interactions. The availability of various modes of meetings allows one to adjust the form of interactions to the topic and/or group under study. For example, voice-only interviews are used mainly in survey research. In qualitative projects they were to a large extent substituted by video conferencing; however, audio-only in-depth interviews may still prove useful in examining hidden groups and controversial topics (see eg. Sipes et al. 2019). In the research project discussed here (immigrant entrepreneurs in the UK), I limited the online in-depth interviews only to meetings with both audio and video recording. Apart from the physical distance, they were in all other aspects "face-to-face" meetings. Such decisions should be made after a comprehensive consideration of the social and psychological context of a project, the wellbeing and vulnerability of the respondents, and the level of sensitivity of the topic in question. The issue under study was the labour-market activity of migrants, which generally did not explore sensitive topics such as sexual identity, religious beliefs or illegal activities (even though, in a few cases, the issues of the grey economy were examined). Therefore online, face-to-face interviews were a safe method to choose, since they enabled better contact with participants. In conversations without a visual component, the element of depersonalization is stronger, which may translate into excessive briefness of responses, reluctance to develop a narrative or attempts to finish an interview more quickly.

The division between interviews with or without a video-image stream may constitute a more significant demarcation line in determining the quality of data than the distinction between offline and internet-based interviews. Comparisons of online and offline interviews indicate that both methods bring about the same or similar empirical outcomes and do not differ in terms of the conversation duration or the spectrum of topics covered (Johnson et al. 2019; Krouwel et al. 2019; Jenner, Myers 2019). With regard to the quality of empirical material, the results are ambiguous. Some authors point out that offline interviews have more "word density" and more statements are produced to support a similar range of topics (Krouwel et al. 2019; Johnson et al. 2019). On the other hand, other mixed methods projects have recorded the fullest and richest data from online rather than offline interviews (Nehls et al. 2015). This case study of migrant entrepreneurs demonstrated that informational thickness of interviews is achievable in both online and offline interviews. However, in internet-based research, technical issues, such as problems with the connection or using the video-conferencing application, may 
have an adverse effect on the final content of a conversation. This begs the question of how to treat interviews which unexpectedly turn into audio-only interviews (e.g. turning off the camera, or an inactive computer camera). A rational solution would be to create scientific protocols to smoothly react and proceed in the case of typical communication barriers of online interviews: technical problems and interruptions of connections, a low-quality internet connection, and difficulties with video or audio recording. Even if they do not lead to a premature end to the interview, they may result in abbreviated responses or the omission of some essential aspects in respondents' narratives.

\section{ETHICS OF ONLINE RESEARCH AND ARCHIVING INTERNET-BASED INTERVIEWS}

The challenges of online migration research originate from its location at the intersection of fieldwork involving minority/vulnerable groups and internet-based research, which makes it particularly demanding. Many ethical codes of conduct for sociologists do not specify the challenges of online research (especially internet-based interviews) or distinguish this mode of research from other types of sociological inquiry. Introducing more tailored provisions and protocols designed specifically to address the virtual aspect of studies would provide researchers with transparent clues in ambiguous situations. Internet research raises concerns about the privacy of participants, since all factors related to the identification and location of an individual can be determined by a computer's IP number, and some video-conferencing applications may collect additional information about the interaction of participants during an online interview (Sullivan 2012). Additional reservations concern hidden research, conducted without the knowledge or consent of participants. This encompasses activities such as analysis of social media activities, statements made on Facebook, Instagram etc. Such studies may potentially breach the privacy of individuals under study in situations where the boundaries between anonymity and recognizability are blurred.

Online research requires additional levels of personal data protection. Researchers using video-conferencing applications process not only respondents' voices, but also their visual images, which affects the scope of personal data transmitted by participants. This adds additional layers of complexity to the already challenging anonymization of qualitative research. Moreover, in qualitative research, due to the nature of open questions, particular interviews may differ with regard to their thematic scope, and some respondents may disclose additional sensitive information, which deserves an increased level of protection. Qualitative narratives are individualized, not standardized, as in the case of survey responses; anonymizing these types of 
fieldwork collections sometimes requires the modification of essential parts of narratives, and for these reasons the archived material may not be fit for secondary analyses.

An increasingly important challenge in social sciences is archiving research data, especially in light of a new Directive (EU) 2019/1024 of the European Parliament and of the Council of 20 June 2019 on open data and the re-use of public sector information. It envisages that all archived projects in the European Union will be made available free of charge to every individual who wishes to access the data. The Directive is currently undergoing implementation in EU member countries. Within qualitative research, two approaches to archiving may be distinguished. One is applied with regard to projects which concern sensitive topics or vulnerable or hidden populations: the significance of archiving is limited, and the key data about informants should not be stored or publicized. The second approach is liberal and concerns projects where respondents give their informed consent to publicize their personal data and all the elements of their narratives (e.g. oral history projects). These issues should be considered before archiving. The archiving of research projects where interviewees give their full consent to broadcast the data has been made simpler in the internet era. The second type of archiving (vulnerable or hidden populations/sensitive topics) will meet additional difficulties in connection with online research. Audio-video recordings of interviews are even more difficult to anonymize than written transcripts. The combination of sound and image unambiguously identifies a respondent. In the case of immigrant populations, one should also take into account various systems of personal data protection in different countries, since research projects often surpass the borders of a single state. Within the European Union, the standards are unified, but in many AngloSaxon countries, which are typical migrant destinations, the provisions may be different. In the case of empirical material which is processed in Poland after the collection phase, the Polish regulations are binding. Moreover, the psychological aspect of the archiviation should be noted. In some cases, the anticipation of archivization during an interview may work as the de facto introduction of a third observer. The conversation no longer takes place between the two interlocutors, and the respondents' statements are addressed not only to the researcher, but also, for the sake of appearances, to a broader outside public.

Another ethical issue is health concerns. This dimension has become increasingly important in light of the pandemic. The problems of the pandemic translate into further challenges connected with ensuring safety from contracting coronavirus for the researcher and informants, strategies of fieldwork with the participation of the most Covid-vulnerable individuals and groups, and preventing the "pandemic exclusion" of certain individuals or segments of the community under study. 


\section{ONLINE QUALITATIVE RESEARCH AND THE CORONAVIRUS PANDEMIC}

The coronavirus pandemic has added a new context and new meanings to online research, validating it as a legitimate and safe research strategy. In the project discussed here, new challenges resulting from the pandemic comprised health concerns and associated issues of: 1) sample construction, hierarchy of risks, and subjective perceptions of essential activities; 2) interactions with respondents who denied the existence of the pandemic; 3) compliance with legal restrictions; 4) taking into consideration the changes of organizational culture and new types of online activities on migrant entrepreneurs.

Eliminating or disavowing internet-based research may lead to the indirect deformation of a sample; for example, through avoiding research in locations hardly touched by coronavirus, or by rejections of interview invitations by respondents who are in high risk groups prone to more severe Covid infection. More generally, online research also allows for the inclusion of participants with disabilities. Such informants are usually taken into consideration in projects focusing on their disability status. Other social issues and phenomena concern this group as well - an obvious but understated observation - whereas such respondents may be omitted in the sample construction as a consequence of more difficult access to them. In doing this, researchers may unintentionally replicate the perception bias of describing such individuals solely against the backdrop of their disability status. Another aspect of health concern is the participation of the researchers. Within research project teams, focusing solely on face-to-face research may also lead to privileged treatment of researchers who do not have other concomitant or underlying health issues. On the other hand, the possibility of conducting internetbased research from another country or city enables a quick reaction to changes of the pandemic situation and makes the researchers more independent from temporary lockdowns, mobility problems, difficult access to respondents during quarantines, and other state-imposed limitations on real-life meetings. During the pandemic, the risk to health arises not only from offline interviews as they are, but also from using public transport, such as aircraft, trains, buses and metro systems, either internationally or within a geographically smaller space.

Another factor influencing research is the differentiated hierarchy of risks established by researchers and individuals under study. The perception of hazards may be different for a researcher and their informants. For an interviewer, the meeting is an essential and key part of their work. For respondents, participation in research is an additional activity which usually offers little or no financial incentive. Face-to-face conversation combines a higher risk of infection with the moderate significance of this activity from the interviewees, which means that invitations to participate in research may easily be rejected. 
Throughout the offline part of the research on Polish migrant entrepreneurs in the UK, the additional health risk stemmed from the non-compliance of some informants with sanitary restrictions. There were respondents who openly declared themselves to be 'coronasceptic' (it must be emphasized that not all of them adopted this approach). The question of a potential reaction in such cases constitutes part of a larger controversy concerning whether one should interfere with the behaviours, attitudes and opinions of research participants during fieldwork. Such interventions may affect the trust towards a researcher and influence the provision of information.

Online research concerns both avoiding the threat to health and the appropriate use of new opportunities. It also enables investigator participation in events and activities which are organized by the immigrants only via internet tools. Online research methods reflect the actual changes in professional activities of migrant entrepreneurs, who arrange virtual business meetings, networking webinars, and perform the vast majority of their work online. The research activities in the project included: participation in mailing lists and newsletters addressed to Polish migrant entrepreneurs; observation of immigrant groups on social media; and observation of publicly available professional profiles of migrant entrepreneurs on businessoriented online networks. Neglecting internet-based research methods would mean the omission of a whole spectrum of activities which have fully transitioned from the offline to the online mode.

The pandemic also has a significant legal dimension and requires researchers to be compliant with the anti-Covid restrictions established on a national or regional level, which are frequently modified. The provisions were particularly severe in London, where the researcher was based for the duration of the project, including limiting the possibilities of travel within the UK, as well as abroad, and a ban on household mixing - although more lenient and stricter regulations applied alternately throughout various phases of the pandemic. The research strategy had to be adapted to the new regulations as they changed on a weekly and monthly basis. Apart from online interviews, the strategy included participant observation, on-site visits in Polish firms, photographic documentation of ethnic districts and ethnic business ventures. In addition to interviews, I also conducted short unstructured on-site conversations with self-employed Poles and their collaborators, which enabled me to see the members of the group under study in their work environment. It was not always followed by a structured online or offline interview, but allowed me to overcome the social distance without long-lasting close face-to face communication, which would be risky due to the pandemic.

The structure and character of empirical research is not limited to interactions between a researcher and respondents. The research context also encompasses other subjects which influence the realization and effects of scientific projects. Therefore, one should also take into consideration the approaches of other actors in 
the academic environment. The pandemic led to greater flexibility from scientific journals, which are interested in publishing the most up-to-date research about the current, dynamically changing situation. They accept research conducted using video-conference tools, since this type of project usually contains the most recent empirical results. Moreover, in the case of research grants, the necessity to adhere to the schedule implies the acceptance of online research, especially when the alternative would be the renouncement of empirical study or only conducting it to a limited extent.

\section{CONCLUSION: DIGITALIZATION OF (QUALITATIVE) RESEARCH}

The table below presents four methodological contexts in which digital/online practices and procedures are present and which were discussed in the article. The particular components depict the cognitive potential of the internet-induced methodological shift in various phases of a project: recruitment, collecting empirical material, analysis, and archiving.

Table. Digitalization of qualitative research - dimensions

\begin{tabular}{|c|c|c|}
\hline Component & Practices & Opportunities and limitations \\
\hline Recruitment & $\begin{array}{l}\text { Establishing contacts and selection of } \\
\text { respondents with the use of online tools } \\
\text { (social media, emails) }\end{array}$ & $\begin{array}{l}\text { - Digital exclusion } \\
\text { + Digital inclusion }\end{array}$ \\
\hline \multirow[t]{2}{*}{$\begin{array}{l}\text { Empirical data } \\
\text { collection }\end{array}$} & $\begin{array}{l}\text { Remote online communication - interviews } \\
\text { Internet ethnography, analysis of social } \\
\text { media forums }\end{array}$ & \multirow{2}{*}{$\begin{array}{l}\text { + safety from health threats during the } \\
\text { pandemic, lack of health risks } \\
\text { + independence from geographical } \\
\text { distance, more research opportunities for } \\
\text { low-cost projects }\end{array}$} \\
\hline & $\begin{array}{l}\text { Collecting respondent information } \\
\text { available online }\end{array}$ & \\
\hline \multirow[t]{2}{*}{ Analysis } & $\begin{array}{l}\text { Using computer software for qualitative } \\
\text { data analysis }\end{array}$ & $\begin{array}{l}+ \text { fast access to the most recent research } \\
\text { results }\end{array}$ \\
\hline & $\begin{array}{l}\text { Using bibliographic resources through } \\
\text { Google scholar and similar tools }\end{array}$ & $\begin{array}{l}\text { - resources of scientific knowledge } \\
\text { practically reduced to the publications } \\
\text { available online }\end{array}$ \\
\hline Archiving & $\begin{array}{l}\text { Possibility of archiving not only audio but } \\
\text { also video recordings }\end{array}$ & $\begin{array}{l}\text { + access to a full record of interaction } \\
\text { between the researcher and respondent } \\
\text { - stricter rules regulating personal data } \\
\text { protection, which are transmitted to } \\
\text { a larger extent } \\
\text { - anticipation of future archiving of audio } \\
\text { and video recording adversely affects } \\
\text { the narratives and provision of information }\end{array}$ \\
\hline
\end{tabular}


In migration studies, the first two components are especially relevant due to the geographical distance, dynamic mobility of groups under study, and, in many cases, migrants' proficiency in internet usage. Migration studies prove that the choice of research method requires taking into account the complexities of globalization, which encompass territorial mobility, remote communication, and the creation of transnational networks. Another important concern is the pandemic, which has reformulated the possibilities and aims of many social research projects. In qualitative online research, the traditional methods - envisaging face-toface meeting and interactions - must be supplemented with an online research component. The article examined some essential online procedures used by qualitative researchers, with the emphasis on in-depth interviews. Other methods, such as focus groups, were not used in this particular project, but definitely deserve a separate analysis.

The solution to the problems and challenges of online research - such as technological difficulties and social distance - is moving beyond the online/ offline methodological binary. The limitations of online research can be compensated by participant observation, photographic documentation, and combining video-conferencing and face-to-face interviews. The article postulates using both approaches in empirical research, which would allow investigators to comprehensively describe the community under examination and to avoid their research having a fragmentary character. The use of internet tools by researchers has been popularized as a result of the pandemic, but it will not necessarily decrease after the pandemic ends. The implications for future projects include consideration the informants' level of digital proficiency, diversification of approaches and matching the research strategies to respondents' skills, traits, and abilities. Applying methodological hierarchies of a "better" and "worse" research mode does not seem to be appropriate in the case of online/offline research. However, each mode should be used with an understanding of its unique features.

\section{REFERENCES}

Alam, Khorshed and Sophia Imran, (2015),"The digital divide and social inclusion among refugee migrants: A case in regional Australia", Information Technology \& People, Vol. 28 Iss 2 pp. 344-365. https://doi.org/10.1108/ITP-04-2014-0083

Archibald Mandy M. (2016), Investigator Triangulation: A Collaborative Strategy With Potential for Mixed Methods Research, Journal of Mixed Methods Research, Vol 10, Issue 3. https://doi.org/10.1177/1558689815570092

Archibald, M.M., Ambagtsheer, R.C., Casey, M.G., Lawless, M. (2019), Using Zoom videoconferencing for qualitative data collection: perceptions and experiences of researchers and participants, International Journal of Qualitative Methods, vol. 18: 1-8. https://doi.org/10.1177/1609406919874596 
Alencar Amanda (2020), Mobile communication and refugees: An analytical review of academic literature, "Sociology Compass", vo. 14(8). https://doi.org/10.1111/soc4.12802 Paolo Boccagni (2020), Multi-Sited Ethnography, edited by: Paul Atkinson, Sara Delamont, Alexandru Cernat, Joseph W. Sakshaug \& Richard A. Williams

Bos Nathan, Erika Shehan Poole, Kyratso George Karahalios, John Charles Thomas, Marcela Musgrove-Chavez, Sarita Yardi (2009), Research ethics in the facebook era: Privacy, anonymity, and oversight. https://doi.org/10.1145/1520340.1520402

Hamilton Rebekah, Barbara J. Bowers (2006), Internet Recruitment and E-Mail Interviews in Qualitative Studies, Qualitative Health Research 16(6):821-35. https:// doi.org/10.1177/1049732306287599

Carling Jørgen, Marta Bivand Erdal, Rojan Ezzati (2014), Beyond the insider-outsider divide in migration research, Migration Studies, Volume 2, Issue 1, Pages 36-54. https://doi.org/10.1093/migration/mnt022

Denzin Norman K. (1978), The Research Act: A Theoretical Introduction to Sociological Methods, Routledge.

Faist Thomas, Margit Fauser, Eveline Reisenauer (2013) Transnational Migration. Cambridge: Polity Press.

Fosslien L., M. West Duffy (2020), How to combat zoom fatigue, Harvard Business Review.

Gray, Lia M; Wong-Wylie, Gina; Rempel, Gwen R; Cook, Karen (2020), Expanding Qualitative Research Interviewing Strategies: Zoom Video Communications, The Qualitative Report; volume 25, number 5, (May 2020): 1292-1301.

Guthrie Susan, Daniela Rodriguez Rincon, Gordon McInroy, Becky Ioppolo, Salil Gunashekar (2019), Measuring bias, burden and conservatism in research funding processes, F1000Research 2019, 8:851. https://doi.org/10.12688/f1000research.19156.1

Helsper, Ellen J., Reisdorf, Bianca C. (2016), The emergence of a "digital underclass" in Great Britain and Sweden: changing reasons for digital exclusion. "New Media \& Society". https://doi.org/10.1177/1461444816634676

James, Nalita, Busher, Hugh (2012) Internet Interviewing, J. Gubrium, J. Holstein, A. Marvasti K. McKinney (eds) Handbook of Interview Research, 2nd edition, New York: Sage

Janghorban Roksana, Robab Latifnejad Roudsari \& Ali Taghipour (2014) Skype interviewing: The new generation of online synchronous interview in qualitative research, International Journal of Qualitative Studies on Health and Well-being, 9:1, 24152. https://doi.org/10.3402/qhw.v9.24152

Jenner Brandy M., Kit C. Myers (2019), Intimacy, rapport, and exceptional disclosure: a comparison of in-person and mediated interview contexts, International Journal of Social Research Methodology, Volume 22, Issue 2. https://doi.org/10.1080/136455 79.2018.1512694

Johnson David, Christopher P. Scheitle, Elaine Howard Ecklund (2019), Beyond the In-Person Interview? How Interview Quality Varies Across In-person, Telephone, and Skype Interviews, "Social Science Computer Review". https://doi. org/10.1177/0894439319893612

Kathrin Kissau, Uwe Hunger (2010), The internet as a means of studying transnationalism and diaspora, in: Rainer Bauböck, Thomas Faist (ed.), Diaspora and Transnationalism: 
Concepts, Theories and Methods, IMISCOE Research Series, Amsterdam University Press, pp. 245-266.

Kazmer Michelle M. \& Bo Xie (2008), Qualitative Interviewing In Internet Studies: Playing With The Media, Playing With The Method, Information, Communication \& Society, Volume 11, 2008 - Issue 2. https://doi.org/10.1080/13691180801946333 Konecki KrzysztofT. (2008), Triangulation and Dealing with The Realness of Qualitative Research, Qualitative Sociology Review, Volume IV, Issue 3.

Krouwel Matthew, Kate Jolly \& Sheila Greenfield (2019), Comparing Skype (video calling) and in-person qualitative interview modes in a study of people with irritable bowel syndrome - an exploratory comparative analysis, BMC Medical Research Methodology volume 19. https://doi.org/10.1186/s12874-019-0867-9

Kutscher Nadia, Lisa-Marie Kreß (2016), 'Internet is the same like food' - An empirical study on the use of digital media by unaccompanied minor refugees in Germany, "Transnational Social Review. A Social Work Journal”, Vol. 6(1-2), p. 200-203. https://doi.org/10.1080/21931674.2016.1184819

Lo Iacono Valeria, Paul Symonds, David H.K. Brown (2016), Skype as a Tool for Qualitative Research Interviews, Sociological Research Online Volume: 21 issue: 2, page(s): 103-117. https://doi.org/10.5153/sro.3952

Maitland Carleen, Xu Ying (2015, March). A social informatics analysis of refugee mobile phone use: A case study of Za'atari Syrian refugee camp. TPRC 43: The 43rd Research Conference on Communication, Information and Internet Policy Paper. https://doi.org/10.2139/ssrn.2588300

Mann Chris, Fiona Stewart (2000), Internet Communication and Qualitative Research: A Handbook for Researching Online. Sage. https://doi.org/10.4135/9781849209281 Meho Lokman I. (2006), E-Mail Interviewing in Qualitative Research: A Methodological Discussion. https://doi.org/10.1002/asi.20416

Mirick, Rebecca G., Wladkowski, Stephanie P. (2019). Skype in Qualitative Interviews: Participant and Researcher Perspectives. The Qualitative Report, 24(12), 3061-3072. Retrieved from https://nsuworks.nova.edu/tqr/vol24/iss 12/9

Nehls Kimberly, Brandy D. Smith, Holly A. Schneider (2015), Video-Conferencing Interviews as a Data Collection Method, In: Enhancing Qualitative and Mixed Methods Research with Technology. (pp.140-157), IGI-Global Publishing, Editors: Shalin Hai-Jew. https://doi.org/10.4018/978-1-4666-6493-7.ch006

O'Connor Henrietta, Clare Madge (2003), "Focus groups in cyberspace": Using the Internet for qualitative research, Qualitative Market Research, volume 6(2): 133143. https://doi.org/10.1108/13522750310470190

Pedro J. Oiarzabal, Ulf-Dietrich Reips (2012): Migration and Diaspora in the Age of Information and Communication Technologies, Journal of Ethnic and Migration Studies, 38:9,1333-1338. https://doi.org/10.1080/1369183X.2012.698202

Reips, Ulf-Dietrich (2008). How Internet-mediated research changes science. In A. Barak (Ed.), Psychological aspects of cyberspace: Theory, research, applications (p. 268-294). Cambridge University Press. https://doi.org/10.1017/ CBO9780511813740.013

RichterAlexander(2020), Locked-down digital work, International Journal of Information Management, Volume 55. https://doi.org/10.1016/j.ijinfomgt.2020.102157 
Robinson, O. C. (2014). Sampling in interview-based qualitative research: A theoretical and practical guide. Qualitative Research in Psychology, 11(1), 25-41. https://doi.or $\mathrm{g} / 10.1080 / 14780887.2013 .801543$

Salmons Janet (2014), Qualitative Online Interviews: Strategies, Design, and Skills, Sage Publications.

Sipes Jessica, Lynne Diane Roberts, Barbara Mullan (2019), Voice-only Skype for use in researching sensitive topics: a research note, Qualitative Research in Psychology. https://doi.org/10.1080/14780887.2019.1577518

Smets Kevin (2018), The way Syrian refugees in Turkey use media: Understanding "connected refugees" through a non-media-centric and local approach. Communications, vol. 43(1), 113-123. https://doi.org/10.1515/commun-2017-0041

Stieger Stefan, Anja S. Göritz (2006), Using instant messaging for Internet-based interviews, CyberPsychology \& Behavior, vol. 9, number 5. https://doi.org/10.1089/ cpb.2006.9.552

Strauss, A., \& Corbin, J. (1998). Basics of qualitative research: Techniques and procedures for developing grounded theory (2nd ed.). Sage Publications, Inc.

Sullivan, Jessica R. (2012) "Skype: An Appropriate Method of Data Collection for Qualitative Interviews?,” The Hilltop Review: Vol. 6: Iss. 1, Article 10.

Symonds, V., Symonds, P., \& Brown, D. H. K. (2016). Skype as a Tool for Qualitative Research Interviews. Sociological Research Online, 21(2), [12]. https://doi.org/10.5153/ sro.3952

Vertovec Steven (2009), Transnationalism, London, Routledge. https://doi. org/10.4324/9780203927083

Wall, M., Campbell, M., \& Janbek, D. (2017). Syrian refugees and information precarity. New Media \& Society, 19(2), 240-254. https://doi.org/10.1177/1461444815591967

Weller Susie (2017), Using internet video calls in qualitative (longitudinal) interviews: some implications for rapport, Volume 20, 2017 - Issue 6. https://doi.org/10.1080/1 3645579.2016.1269505

Witteborn Saskia (2018). The digital force in forced migration: Imagined affordances and gendered practices. Popular Communication, vol. 16(1), 21-31. https://doi.org/ 10.1080/15405702.2017.1412442

Wiederhold Brenda K. (2020), Connecting Through Technology During the Coronavirus Disease 2019 Pandemic: Avoiding "Zoom Fatigue", "Cyberpsychology, Behavior, And Social Networking", Volume 23, Number 7, 2020. https://doi.org/10.1089/ cyber.2020.29188.bkw

Wilkerson J. Michael, Alex Iantaffi, Jeremy A. Grey, Walter O. Bockting, B. R. Simon Rosser (2014), Recommendations for Internet-Based Qualitative Health Research With Hard-to-Reach Populations, Qualitative Health Research 2014 Apr; 24(4): 561-574. https://doi.org/10.1177/1049732314524635

Wittel Andreas (2000), Ethnography on the Move: From Field to Net to Internet, "Forum: Qualitative Social Research", Volume 1, No. 1, Art. 21.

Wylegała Anna (2013), Badacz z Polski na Ukrainie: problemy metodologiczne, „Przegląd Socjologii Jakościowej” issue IX(4). 
